Research Paper

\title{
Effect of HMGBI Polymorphisms on Urothelial Cell Carcinoma Susceptibility and Clinicopathological Characteristics
}

\author{
Sheng-Chun Hung1,2, Shian-Shiang Wang1,2,3, Jian-Ri Li1,2,4, Chuan-Shu Chen ${ }^{1,2}$, Chun-Kuang Yang2,

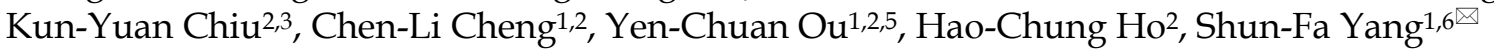 \\ 1. Institute of Medicine, Chung Shan Medical University, Taichung, Taiwan \\ 2. Division of Urology, Department of Surgery, Taichung Veterans General Hospital, Taichung, Taiwan \\ 3. Department of Applied Chemistry, National Chi Nan University, Nantou, Taiwan \\ 4. Department of Medicine and Nursing, Hungkuang University, Taichung, Taiwan Taiwan \\ 5. Department of Urology, Tung's Taichung MetroHarbor Hospital, Taichung, Taiwan \\ 6. Department of Medical Research, Chung Shan Medical University Hospital, Taichung, Taiwan \\ $\square$ Corresponding author: Shun-Fa Yang, PhD. Institute of Medicine, Chung Shan Medical University, 110, Section 1, Chien-Kuo N. Road, Taichung, Taiwan, \\ ROC. Fax: 886-4-24723229. E-mail: ysf@csmu.edu.tw \\ (C) Ivyspring International Publisher. This is an open access article distributed under the terms of the Creative Commons Attribution (CC BY-NC) license \\ (https://creativecommons.org/licenses/by-nc/4.0/). See http://ivyspring.com/terms for full terms and conditions.
}

Received: 2018.06.15; Accepted: 2018.10.18; Published: 2018.11.22

\begin{abstract}
The high mobility group box 1 gene $(H M G B I)$ plays a prominent role in cancer progression, angiogenesis, invasion, and metastasis. This study explored the effect of $H M G B I$ polymorphisms on clinicopathological characteristics of urothelial cell carcinoma (UCC). In total, 1293 participants (431 patients with UCC and 862 healthy controls) were recruited. Four single-nucleotide polymorphisms (SNPs) of HMGBI (rs1412125, rs1360485, rs1045411, and rs2249825) were assessed using TaqMan real-time polymerase chain reaction assay. The results indicated that individuals carrying at least one T allele at rs 1045411 had a lower risk of UCC than those with the wild-type allele [adjusted odds ratio $=0.722,95 \%$ confidence interval $(\mathrm{Cl})=0.565-0.924$ ] . Furthermore, female patients with UCC carrying at least one T allele at rs 1045411 were at a lower invasive tumor stage than those with the wild-type allele [odds ratio $(\mathrm{OR})=0.396,95 \% \mathrm{Cl}=$ 0.169-0.929], similar to nonsmoking patients $(\mathrm{OR}=0.607,95 \% \mathrm{Cl}=0.374-0.985)$. In conclusion, this is the first report on correlation between HMGBI polymorphisms and UCC risk. Individuals carrying at least one T allele at rs 1045411 are associated with a lower risk of UCC and a less invasive disease in women and nonsmokers.
\end{abstract}

Key words: high mobility group box 1 , polymorphism, urothelial cell carcinoma

\section{Introduction}

Bladder cancer (BC) is the seventh most common cancer in men and the 11th most common cancer in both sexes worldwide, with an incidence of 9.0 and 2.2 per 100,000 person-years in men and women, respectively [1]. More than $95 \% \mathrm{BCs}$ are urothelial cell carcinomas (UCCs) and constitute the most frequent malignant tumors of the urinary tract [2]. Overall, $50 \%-70 \%$ of patients with UCC experience a recurrence within 5 years; of them, 10\% progress into invasive disease, a highly aggressive malignancy that causes mortality [3].
In Taiwan, BC is the ninth and 16th most common cancer in men and women, respectively, with a male-to-female predominance ratio of 2.6:1 [4]. The geographic characteristic of BC is particularly noted in an arseniasis-endemic area in Taiwan, which is associated with black foot disease and has contributed to a higher incidence of UCC, skin cancer, and lung cancer [5].

Environmental factors, such as tobacco use and exposure to aromatic amines, lead to carcinogenesis of $\mathrm{BC}$ in well-established data [6-8]. Both genetic factors 
and single-nucleotide polymorphisms (SNPs) are pivotal in BC tumorigenesis and progression, such as an oncogene or a tumor suppressor gene [9-12]. Our previous studies have revealed an association between CA9, ICAM1, and EZH2 polymorphisms and UCC susceptibility and clinicopathological characteristics, which may be a potential marker that indicates tumor treatment and progression [13-15].

The high mobility group box 1 protein (HMGB1), belonging to the high mobility group protein family, demonstrates rapid mobility in sodium dodecyl sulfate-polyacrylamide gel electrophoresis gels; it was first purified from calf thymus nuclei in the 1970s. It contains two 80-amino acid DNA-binding domains and a negatively charged C-terminus [16, 17]. HMGB1 functions as a chromatin structural protein in the nucleus and as a proinflammatory cytokine extracellularly [18]. In the nucleus, it acts as a DNA chaperone or a nonhistone DNA-binding protein that can bend DNA and promote the formation of complexes comprising several transcription factors [19]. Extracellular HMGB1 occurs if HMGB1 is passively leaks from cells when cell membrane integrity is lost during necrosis; thus, it is a reliable indicator for necrosis. Extracellular HMGB1 binds with high affinity to the receptor for advanced glycation end products; it is a potent mediator of inflammation [20]. Furthermore, HMGB1 overexpression is an indicator for malignant tumorigenesis, proliferation, invasion, and migration [21-24].

HMGB1 overexpression in UCC is associated with tumor progression and angiogenesis [25, 26], whereas HMGB1 knockdown is associated with suppressed cell growth, migration, and induced cell apoptosis, and it is sensitive to radiotherapy and cisplatin-based chemotherapy [27, 28]. Although HMGB1 is a poor prognosis factor, it is a powerful cytokine released by UCC cells, which directs host immune responses and potentiates the cytotoxicity effects of bacillus Calmette-Guérin vaccine, which is the standard treatment for nonmuscle-invasive $\mathrm{BCs}$ [29]. Therefore, HMGB1 acts as a potential molecule marker for predicting prognosis and treatment response.

Single-nucleotide polymorphisms (SNPs) are the most common type of DNA sequence variation influencing the progression of various diseases [30]. The effect of HMGB1 polymorphisms on clinicopathological features of cancers, Including lung cancer, gastric cancer, hepatocellular carcinoma, uterine cancer, and oral squamous cell carcinoma, has been reported [31-35]. Nevertheless, few studies have investigated the association between HMGB1 variants and UCC risk and prognosis. The present study investigated the relationship of four HMGB1 SNPs, namely rs1412125, rs2249825, rs1045411, and rs1360485, with UCC susceptibility and clinicopathological characteristics.

\section{Materials and Methods}

\section{Subjects and Specimen Collection}

The study recruited 431 patients (272 men and 159 women, with a mean age of 68.60 years) in 2011-2016 at Taichung Veterans General Hospital in Taichung, Taiwan. All patients have pathology proved urothelial cell carcinoma of urinary bladder. For the control group, during the same study period, 862 ethnic individuals were enrolled and entered the physical examination. Approval was obtained from the Institutional Review Board (IRB) of Taichung Veterans General Hospital (IRB No. CF11094). We used a questionnaire to obtain information on patient exposure to tobacco consumption for both cases and controls.

\section{HMGBI SNP selection}

We included four HMGB1 SNPs (rs1412125, rs2249825, rs1045411, and rs1360485) in the HapMap Chinese Han Beijing population. Moreover, these four HMGB1 genetic polymorphisms were selected based on their potential involvement in the several cancer types $[31,33,36]$. The specific heterozygosity frequencies using the East Asian population of HMGB1 rs1412125, rs2249825, rs1045411, and rs1360485 were $44.4 \%, 28.0 \%, 33.5 \%$ and $36.3 \%$, respectively.

\section{Genomic DNA extraction}

Total genomic DNA from whole blood specimens were isolated by QIAamp DNA blood mini kits (Qiagen, Valencia, CA) as previously described [37]. DNA was dissolved in TE buffer and stored at $-20^{\circ} \mathrm{C}$ until performing Real-time quantitative PCR analysis.

\section{Real-time quantitative PCR}

Total four SNPs of HMGB1 were examined by using TaqMan SNPs Genotyping Assays (Applied Biosystems, Warrington, UK), according to the manufacturer's protocols as previously described [31,33].

\section{Statistical analysis}

The Mann-Whitney U-test was used to compare differences in distributions of patient demographic characteristics between the control and UCC groups. Differences between the two groups were considered significant if $p$ values $<0.05$. The adjusted odds ratios (AORs) and 95\% confidence intervals (CIs) of the association between clinicopathological characteristics and genotype frequencies were assessed using multiple logistic regression models, after controlling for other covariates. Data were analyzed with SAS 
statistical software (vers. 9.1, 2005; SAS Institute, Cary, NC).

\section{Results}

The patient characteristics and clinical parameters are listed in Table 1 . The study population was Taiwanese, with a predominance of men with UCC (n $=272,63.1 \%)$. At diagnosis, 235 patients had nonmuscle-invasive $\mathrm{BC}(54.5 \%)$ and $196 \mathrm{had}$ muscle-invasive BC (45.5\%). Furthermore, 378 and 53 patients had high- and low-grade tumors, respectively. Lymph node status ( $\mathrm{n}=51,11.8 \%$ ) and metastasis $(\mathrm{n}=14,3.2 \%)$ were evaluated through contrast-enhanced computed tomography. To diminish possible interference, we estimated the adjusted odds ratios (AORs) with their 95\% confidence intervals (CIs) by using multiple logistic regression models, with adjustments for age, sex, and tobacco consumption.

Table 2 lists the distribution frequency of HMGB1 genotypes in the 862 healthy controls and 431 patients with UCC. In both groups, the highest distribution frequencies was demonstrated by homozygous TT at rs1412125 and rs1360485 and by homozygous CC at rs1045411 and rs2249825. The patients carrying at least one $\mathrm{T}$ allele at rs1045411 (CT or TT) presented a lower UCC risk than did a those carrying the wild type $(\mathrm{CC}$; $\mathrm{AOR}=0.722,95 \% \mathrm{CI}=$ $0.565-0.924, p=0.010)$. Furthermore, the CC genotype at rs1412125 also showed a decreased UCC risk compared with the wild type after adjustment (AOR = $0.555,95 \% \mathrm{CI}=0.341-0.902, p=0.018)$.

Regarding the tumor stage, female patients with UCC carrying rs1045411 CT+TT demonstrated a lower risk of stage T1-T4 UCC than did those carrying the wild type [odds ratio $(\mathrm{OR})=0.396,95 \% \mathrm{CI}=$ 0.169-0.929, $p=0.030$; Table 3]. Furthermore, rs1045411 CT+TT appeared to be a protective factor in nonsmoking patients: it significantly reduced the muscle-invasive $\mathrm{UCC}$ risk $(\mathrm{OR}=0.607,95 \% \mathrm{CI}=$ $0.374-0.985, p=0.043$ ). There was no significant difference in lymph node status, metastasis, or histopathologic grading between the two groups in a subgroup analysis.

\section{Discussion}

We examined the association between HMGB1 SNPs and susceptibility to and clinicopathological features of UCC. The results revealed that patient carrying at least one $\mathrm{T}$ allele at rs1045411 had a significantly lower risk of UCC than did those carrying a wild type (AOR $=0.722)$. Furthermore, this SNP demonstrated a less invasive cancer stage in women and nonsmokers in subgroup analysis, which appeared to have a protective factor. The CC mutation at rs1412125 also led to a lower UCC risk (AOR = $0.555)$.

Table 1. The distributions of demographical characteristics in 862 controls and 431 patients with UCC.

\begin{tabular}{llll}
\hline Variable & Controls (N=862) & Patients (N=431) & p value \\
\hline Age (yrs) & Mean \pm S.D. & Mean \pm S.D. & \\
& $57.18 \pm 9.99$ & $68.60 \pm 11.81$ & $\mathrm{p}<0.001$ \\
Gender & & & \\
Male & $566(65.7 \%)$ & $272(63.1 \%)$ & \\
Female & $296(34.3 \%)$ & $159(36.9 \%)$ & $\mathrm{p}=0.365$ \\
Tobacco consumption & & & \\
No & $562(65.2 \%)$ & $300(69.6 \%)$ & \\
Yes & $300(34.8 \%)$ & $131(30.4 \%)$ & $\mathrm{p}=0.113$ \\
Stage & & & \\
Non muscle invasive & & $235(54.5 \%)$ & \\
tumor (pTa-pT1) & & & \\
Muscle invasive tumor & & $196(45.5 \%)$ & \\
(pT2-pT4) & & & \\
Tumor T status & & & \\
Ta & & $30(20.9 \%)$ & \\
T1-T4 & & $341(79.1 \%)$ & \\
Lymph node status & & $380(88.2 \%)$ & \\
N0 & & $51(11.8 \%)$ & \\
N1+N2 & & & \\
Metastasis & & & \\
M0 & & & \\
M1 & & & \\
Histopathologic grading & & & \\
Low grade & & & \\
High grade & & & \\
\hline
\end{tabular}

Mann-Whitney U test was used between controls and patients with UCC.

Accumulating evidence has indicated that genetic susceptibility and familial factors, along with environmental factors, may affect BC risk and incidence. A study reported that family history of cancer among first degree relatives, particularly among relatively young patients, was associated with shared environmental exposure, a potential confounding factor [38]. Genome-wide association studies have also identified several possible susceptibility genetic loci associated with BC risk [39-41]. Furthermore, smoking is the most well-known risk factor for BC, causing BC in $50 \%-65 \%$ and $20 \%-30 \%$ of male and female patients, respectively - regardless of being current and former smokers [42, 43]. The difference in the prevalence among both sexes has also been established in a population-based study, which demonstrated a higher prevalence in men, possibly because of a higher frequency of tobacco use and increased exposure to chemicals [44].

HMGB1 mRNA and protein overexpression is associated with poorer prognosis with various cancer types [24]. Higher HMGB1 expression is also found in several malignancies, including lung cancer, hepatocellular carcinoma, gastric cancer, uterine cancer, and oral squamous cell carcinoma [31-35]; thus, HMGB1 is an oncoprotein. However, because its 
paradoxical roles as a tumor suppressor and an oncogenic factor have been reported, the role of HMGB1 in cancer progression remains unclear [45]. Intracellularly, HMGB1 is a highly conserved chromosomal protein acting as a DNA chaperone, whereas extracellularly, it acting with cytokines, chemokines, and growth factors [45].

HMGB1 overexpression has been associated with poor prognosis, progression, and angiogenesis in $\mathrm{BC}$ in both clinical and animal studies [25, 26]. In the present study, four HMGB1 SNPs were assessed in patients with UCC and healthy controls, with the results indicating that CT or CT+TT at rs1045411 is significantly associated with lower UCC risk. This result is consistent with our previous study on hepatocellular carcinoma and oral squamous cell carcinoma, in which we observed that CT and CT+TT at rs1045411 was associated with lower risk of malignancy than was the wild type [31, 33]. The 3 '-untranslated region of HMGB1 covers $2 \mathrm{~kb}$, where rs1045411 is located, which might be the region most sensitive to microRNA epigenetic regulation. Furthermore, compared with the $\mathrm{T}$ allele, the $\mathrm{C}$ allele creates a slight kink in the HMGB1 mRNA structure, resulting in a less negative free-energy state and less stable hybridization and thus altering the HMGB1 mRNA stability and increasing susceptibility to malignant progression [35, 46]. This finding also suggests the synergistic protective effect of at least one $\mathrm{T}$ allele at rs1045411 in women and nonsmokers - established by the lower UCC risk noted in comparison with that in men and smoker, respectively; thus, compared with the wild type, the presence of at least one $\mathrm{T}$ allele at rs1045411 is potentially associated with a less aggressive UCC. In addition, individuals with CC at rs1412125 were associated with less UCC risk after adjustment. This echoes our previous finding that one C allele at rs1412125 is associated with less distal metastasis risk in hepatocellular carcinoma [31]. This SNP, situated at a transcription factor binding site, may be one of the most common elements in eukaryotic promoters [47, 48]. Although the actual mechanism of action of rs1412125 is unclear, the C allele potentially also reduces lung cancer risk [34].

To our knowledge, no study has examined HMGB1 SNPs with regard to UCC susceptibility and clinicopathology. However, this study has several limitations. First, treatment and survival data were lacking; these data may aid in enhanced interpretation of HMGB1 SNP mechanism in a larger cohort study. Second, a study using larger sample size is required to confirm the actual function and statistical significance of our results. A large-scale study verifying the association of HMGB1 SNP with UCC risk is warranted.
Table 2. Distribution frequency of $H M G B I$ genotypes in 862 controls and 431 UCC patients.

\begin{tabular}{|c|c|c|c|c|}
\hline Variable & $\begin{array}{l}\text { Controls }(\mathrm{N}= \\
862) \mathrm{n}(\%)\end{array}$ & $\begin{array}{l}\text { Patients(N= } \\
431) n(\%)\end{array}$ & OR $(95 \% \mathrm{CI})$ & AOR $(95 \%$ CI) \\
\hline \multicolumn{5}{|l|}{ rs1412125 } \\
\hline TT & $448(52.0 \%)$ & $231(53.6 \%)$ & 1.00 & 1.00 \\
\hline $\mathrm{TC}$ & $336(39.0 \%)$ & $175(40.6 \%)$ & $\begin{array}{l}1.010 \\
(0.793-1.287)\end{array}$ & $1.015(0.792-1.301)$ \\
\hline $\mathrm{CC}$ & $78(9.0 \%)$ & $25(5.8 \%)$ & $\begin{array}{l}0.622 \\
(0.386-1.002)\end{array}$ & $0.555(0.341-0.902)^{*}$ \\
\hline $\mathrm{TC}+\mathrm{CC}$ & $414(48.0 \%)$ & $200(46.4 \%)$ & $\begin{array}{l}0.937 \\
(0.743-1.181)\end{array}$ & $0.922(0.727-1.169)$ \\
\hline \multicolumn{5}{|l|}{ rs1360485 } \\
\hline TT & $474(55.0 \%)$ & 255 (59.2\%) & 1.00 & 1.00 \\
\hline TC & $327(37.9$ & $154(35.7 \%)$ & $\begin{array}{l}0.875 \\
(0.685-1.118)\end{array}$ & $0.874(0.680-1.123)$ \\
\hline $\mathrm{CC}$ & $61(7.1 \%)$ & $22(5.1 \%)$ & $\begin{array}{l}0.670 \\
(0.402-1.117)\end{array}$ & $0.646(0.384-1.088)$ \\
\hline $\mathrm{TT}+\mathrm{CC}$ & $388(45.0 \%)$ & $176(40.8 \%)$ & $\begin{array}{l}0.843 \\
(0.667-1.066)\end{array}$ & $0.837(0.659-1.064)$ \\
\hline \multicolumn{5}{|l|}{ rs1045411 } \\
\hline CC & $503(58$ & $283(65.7 \%)$ & 1.00 & 1.00 \\
\hline CT & $304(35.3 \%)$ & $127(29.5 \%)$ & $\begin{array}{l}0.743 \\
(0.576-0.956)^{*}\end{array}$ & $0.732(0.565-0.949)^{*}$ \\
\hline TT & $55(6.4$ & $21(4.8$ & $\begin{array}{l}0.679 \\
(0.402-1.145)\end{array}$ & $0.668(0.392-1.139)$ \\
\hline $\mathrm{CT}+\mathrm{TT}$ & $359(41.6 \%)$ & 148 & $\begin{array}{l}0.733 \\
(0.576-0.932)^{*}\end{array}$ & $0.722(0.565-0.924)^{*}$ \\
\hline \multicolumn{5}{|l|}{ rs2249825 } \\
\hline CC & 606 & 299 & 1.00 & 1.00 \\
\hline CG & $233(27.0 \%)$ & $121(28.1 \%)$ & $\begin{array}{l}1.053 \\
(0.812-1.365)\end{array}$ & $1.018(0.780-1.327)$ \\
\hline GG & $23(2.7 \%)$ & $11(2.5 \%)$ & $\begin{array}{l}0.969 \\
(0.466-2.015)\end{array}$ & $0.871(0.414-1.834)$ \\
\hline $\mathrm{CG}+\mathrm{GG}$ & $256(29.7 \%)$ & $132(30.6 \%)$ & $\begin{array}{l}1.045 \\
(0.813-1.344)\end{array}$ & $1.004(0.776-1.299)$ \\
\hline
\end{tabular}

The odds ratio (OR) with their $95 \%$ confidence intervals were estimated by logistic regression models. The adjusted odds ratio (AOR) with their $95 \%$ confidence

intervals were estimated by multiple logistic regression models after controlling for age, gender and tobacco consumption. Note: * and Bold text indicated a significant association with $\mathrm{p}$ value $<0.05$.

Table 3. Distribution frequency of the clinical status and $H M G B I$ rs 1045411 genotype frequencies in 159 female patients with UCC.

\begin{tabular}{|c|c|c|c|c|}
\hline \multirow[b]{2}{*}{ Variable } & \multicolumn{4}{|c|}{ HMGB1 (rs1045411) } \\
\hline & $\begin{array}{l}\mathrm{CC}(\%) \\
(\mathrm{n}=103)\end{array}$ & $\begin{array}{l}\mathrm{CT}+\mathrm{TT}(\%) \\
(\mathrm{n}=56)\end{array}$ & OR $(95 \% \mathrm{CI})$ & $\mathrm{p}$ value \\
\hline \multicolumn{5}{|l|}{ Stage } \\
\hline $\begin{array}{l}\text { Non muscle invasive } \\
\text { tumor (pTa-pT1) }\end{array}$ & $50(48.5 \%)$ & $34(60.7 \%)$ & 1.00 & \\
\hline $\begin{array}{l}\text { Muscle invasive tumor } \\
\text { (pT2-pT4) }\end{array}$ & $53(51.5 \%)$ & $22(39.3 \%)$ & $\begin{array}{l}0.610 \\
(0.315-1.182)\end{array}$ & $\mathrm{p}=0.142$ \\
\hline \multicolumn{5}{|l|}{ Tumor T status } \\
\hline Ta & $12(11.7 \%)$ & $14(25.0 \%)$ & 1.00 & \\
\hline $\mathrm{T} 1-\mathrm{T} 4$ & $91(88.3 \%)$ & $42(75.0 \%)$ & $\begin{array}{l}0.396 \\
(0.169-0.929)\end{array}$ & $\begin{array}{l}\mathrm{p}=0.030 \\
*\end{array}$ \\
\hline \multicolumn{5}{|l|}{ Lymph node status } \\
\hline No & $92(89.3 \%)$ & $49(87.5 \%)$ & 1.00 & \\
\hline $\mathrm{N} 1+\mathrm{N} 2$ & $11(10.7 \%)$ & $7(12.5 \%)$ & $\begin{array}{l}1.195 \\
(0.436-3.277)\end{array}$ & $\mathrm{p}=0.729$ \\
\hline \multicolumn{5}{|l|}{ Metastasis } \\
\hline M0 & $102(99.0 \%)$ & 54 (96.4\%) & 1.00 & \\
\hline M1 & $1(1.0 \%)$ & $2(3.6 \%)$ & $\begin{array}{l}3.778 \\
\text { (0.335-42.61 } \\
3)\end{array}$ & $\mathrm{p}=0.250$ \\
\hline \multicolumn{5}{|l|}{ Histopathologic grading } \\
\hline Low grade & $9(8.7 \%)$ & $5(8.9 \%)$ & 1.00 & \\
\hline High grade & $94(91.3 \%)$ & $51(91.1 \%)$ & $\begin{array}{l}0.977 \\
(0.311-3.069)\end{array}$ & $\mathrm{p}=0.968$ \\
\hline
\end{tabular}


Table 4. Distribution frequency of the clinical status and $H M G B I$ rs1045411 genotype frequencies in 300 UCC patients with non-smoker.

\begin{tabular}{|c|c|c|c|c|}
\hline \multirow[b]{2}{*}{ Variable } & \multicolumn{4}{|c|}{ HMGB1 (rs1045411) } \\
\hline & $\begin{array}{l}\text { CC }(\%) \\
(n=194)\end{array}$ & $\begin{array}{l}\mathrm{CT}+\mathrm{TT}(\%) \\
(\mathrm{n}=106)\end{array}$ & OR $(95 \%$ CI $)$ & $\mathrm{p}$ value \\
\hline \multicolumn{5}{|l|}{ Stage } \\
\hline $\begin{array}{l}\text { Non muscle } \\
\text { invasive tumor } \\
\text { (pTa-pT1) }\end{array}$ & $99(51.0 \%)$ & $67(63.2 \%)$ & 1.00 & \\
\hline $\begin{array}{l}\text { Muscle invasive } \\
\text { tumor (pT2-pT4) }\end{array}$ & $95(49.0 \%)$ & $39(36.8 \%)$ & $0.607(0.374-0.985)$ & $\mathrm{p}=0.043^{*}$ \\
\hline \multicolumn{5}{|l|}{ Tumor T status } \\
\hline $\mathrm{Ta}$ & $34(17.5 \%)$ & $27(25.5 \%)$ & 1.00 & \\
\hline T1-T4 & $160(82.5 \%)$ & $79(74.5 \%)$ & $0.622(0.351-1.102)$ & $\mathrm{p}=0.102$ \\
\hline \multicolumn{5}{|c|}{ Lymph node status } \\
\hline No & $174(89.7 \%)$ & $94(88.7 \%)$ & 1.00 & \\
\hline $\mathrm{N} 1+\mathrm{N} 2$ & $20(10.3 \%)$ & $12(11.3 \%)$ & $1.111(0.520-2.371)$ & $\mathrm{p}=0.786$ \\
\hline \multicolumn{5}{|l|}{ Metastasis } \\
\hline M0 & $191(98.5 \%)$ & $104(98.1 \%)$ & 1.00 & \\
\hline M1 & $3(1.5 \%)$ & $2(1.9 \%)$ & $1.224(0.201-7.445)$ & $\mathrm{p}=0.826$ \\
\hline \multicolumn{5}{|c|}{ Histopathologic grading } \\
\hline Low grade & $23(11.9 \%)$ & $13(12.3 \%)$ & 1.00 & \\
\hline High grade & $171(88.1 \%)$ & $93(87.7 \%)$ & $0.962(0.466-1.988)$ & $\mathrm{p}=0.917$ \\
\hline
\end{tabular}

Note: * and Bold text indicated a significant association with $p$ value $<0.05$.

In conclusion, this is the first report to correlate HMGB1 polymorphisms with UCC risk. Individuals carry at least one $\mathrm{T}$ allele at rs1045411 had a lower UCC risk and less invasive disease; most of this population was female and nonsmoking.

\section{Acknowledgments}

This study was supported by Chung Shan Medical University Hospital (CSH-2013-C-007; CSH-2015-C-018).

\section{Competing Interests}

The authors have declared that no competing interest exists.

\section{References}

[1] Jacobs BL, Lee CT, Montie JE. Bladder cancer in 2010: how far have we come? CA Cancer J Clin 2010; 60: 244-272.

[2] Ghoneim MA, Abdel-Latif M, el-Mekresh M, Abol-Enein H, Mosbah A, Ashamallah A, et al. Radical cystectomy for carcinoma of the bladder: 2,720 consecutive cases 5 years later. J Urol 2008; 180: 121-127.

[3] Ferlay J, Soerjomataram I, Dikshit R, Eser S, Mathers C, Rebelo M, et al. Cancer incidence and mortality worldwide: sources, methods and major patterns in GLOBOCAN 2012. Int J Cancer 2015; 136: E359-386.

[4] Colin P, Koenig P, Ouzzane A, Berthon N, Villers A, Biserte J, et al. Environmental factors involved in carcinogenesis of urothelial cell carcinomas of the upper urinary tract. BJU Int 2009; 104: 1436-1440.

[5] Stern MC, Lin J, Figueroa JD, Kelsey KT, Kiltie AE, Yuan JM, et al. Polymorphisms in DNA repair genes, smoking, and bladder cancer risk: findings from the international consortium of bladder cancer. Cancer Res 2009; 69: 6857-6864.

[6] Rouissi K, Stambouli N, Marrakchi R, Slama MR, Cherif M, Sfaxi M, et al. Smoking and polymorphisms in folate metabolizing genes and their effects on the histological stage and grade for bladder tumors. Bull Cancer 2011; 98: E1-10.

[7] Wang L, Wang G, Lu C, Feng B, Kang J. Contribution of the -160C/A polymorphism in the E-cadherin promoter to cancer risk: a meta-analysis of 47 case-control studies. PLoS One 2012; 7: e40219.

[8] Guirado M, Gil H, Saenz-Lopez P, Reinboth J, Garrido F, Cozar JM, et al. Association between C13ORF31, NOD2, RIPK2 and TLR10 polymorphisms and urothelial bladder cancer. Hum Immunol 2012; 73: 668-672
[9] Wang $\mathrm{YH}$, Yeh SD, Shen $\mathrm{KH}$, Shen $\mathrm{CH}$, Tung MC, Liu CT, et al. Association of hOGG1 and XPD polymorphisms with urothelial carcinoma in Taiwan. Anticancer Res 2011; 31: 3939-3944.

[10] Wang YH, Chiou HY, Lin CT, Hsieh HY, Wu CC, Hsu CD, et al. Association between survivin gene promoter $-31 \mathrm{C} / \mathrm{G}$ polymorphism and urothelial carcinoma risk in Taiwanese population. Urology 2009; 73: 670-674.

[11] Lee HL, Chiou HL, Wang SS, Hung SC, Chou MC, Yang SF, et al. WISP1 genetic variants as predictors of tumor development with urothelial cell carcinoma. Urol Oncol 2018; 36: 160.e115-160.e121.

[12] Tung MC, Hsieh MJ, Wang SS, Yang SF, Chen SS, Wang SW, et al. Associations of VEGF-C genetic polymorphisms with urothelial cell carcinoma susceptibility differ between smokers and non-smokers in Taiwan. PLoS One 2014; 9: e91147.

[13] Wang SS, Liu YF, Ou YC, Chen CS, Li JR, Yang SF. Impacts of CA9 gene polymorphisms on urothelial cell carcinoma susceptibility and clinicopathologic characteristics in Taiwan. PLoS One 2013; 8: e82804.

[14] Wang SS, Hsieh MJ, Ou YC, Chen CS, Li JR, Hsiao PC, et al. Impacts of ICAM-1 gene polymorphisms on urothelial cell carcinoma susceptibility and clinicopathologic characteristics in Taiwan. Tumour Biol 2014; 35: 7483-7490.

[15] Yu YL, Su KJ, Hsieh MJ, Wang SS, Wang PH, Weng WC, et al. Impact of EZH2 polymorphisms on urothelial cell carcinoma susceptibility and clinicopathologic features. PLoS One 2014; 9: e93635.

[16] Goodwin GH, Johns EW. Isolation and characterisation of two calf-thymus chromatin non-histone proteins with high contents of acidic and basic amino acids. Eur J Biochem 1973; 40: 215-219.

[17] Ferrari S, Finelli P, Rocchi M, Bianchi ME. The active gene that encodes human high mobility group 1 protein (HMG1) contains introns and maps to chromosome 13. Genomics 1996; 35: 367-371.

[18] Bonaldi T, Talamo F, Scaffidi P, Ferrera D, Porto A, Bachi A, et al. Monocytic cells hyperacetylate chromatin protein HMGB1 to redirect it towards secretion. Embo j 2003; 22: 5551-5560.

[19] Bonaldi T, Langst G, Strohner R, Becker PB, Bianchi ME. The DNA chaperone HMGB1 facilitates ACF/CHRAC-dependent nucleosome sliding. Embo j 2002; 21: 6865-6873.

[20] Scaffidi P, Misteli T, Bianchi ME. Release of chromatin protein HMGB1 by necrotic cells triggers inflammation. Nature 2002; 418: 191-195.

[21] Chen M, Liu Y, Varley P, Chang Y, He XX, Huang H, et al. High-Mobility Group Box 1 Promotes Hepatocellular Carcinoma Progression through miR-21-Mediated Matrix Metalloproteinase Activity. Cancer Res 2015; 75: 1645-1656.

[22] Chung HW, Jang S, Kim H, Lim JB. Combined targeting of high-mobility group box-1 and interleukin-8 to control micrometastasis potential in gastric cancer. Int J Cancer 2015; 137: 1598-1609.

[23] Huber R, Meier B, Otsuka A, Fenini G, Satoh T, Gehrke S, et al. Tumour hypoxia promotes melanoma growth and metastasis via High Mobility Group Box-1 and M2-like macrophages. Sci Rep 2016; 6: 29914.

[24] Wu T, Zhang W, Yang G, Li H, Chen Q, Song R, et al. HMGB1 overexpression as a prognostic factor for survival in cancer: a meta-analysis and systematic review. Oncotarget 2016; 7: 50417-50427.

[25] Wang W, Jiang H, Zhu H, Zhang H, Gong J, Zhang L, et al. Overexpression of high mobility group box 1 and 2 is associated with the progression and angiogenesis of human bladder carcinoma. Oncol Lett 2013; 5: 884-888.

[26] Yang GL, Zhang LH, Bo JJ, Huo XJ, Chen HG, Cao M, et al. Increased expression of HMGB1 is associated with poor prognosis in human bladder cancer. J Surg Oncol 2012; 106: 57-61.

[27] Liao H, Xiao Y, Hu Y, Xiao Y, Yin Z, Liu L. Suppression of Cellular Proliferation and Invasion by HMGB1 Knockdown in Bladder Urothelial Carcinoma Cells. Oncol Res 2014; 22: 235-245.

[28] Shrivastava S, Mansure JJ, Almajed W, Cury F, Ferbeyre G, Popovic M, et al. The Role of HMGB1 in Radioresistance of Bladder Cancer. Mol Cancer Ther 2016; 15: 471-479.

[29] Zhang G, Chen F, Cao Y, Amos JV, Shah G, See WA. HMGB1 release by urothelial carcinoma cells in response to Bacillus Calmette-Guerin functions as a paracrine factor to potentiate the direct cellular effects of Bacillus Calmette-Guerin. J Urol 2013; 190: 1076-1082.

[30] Di Paolo A, Danesi R, Del Tacca M. Pharmacogenetics of neoplastic diseases: new trends. Pharmacol Res 2004; 49: 331-342.

[31] Wang B, Yeh CB, Lein MY, Su CM, Yang SF, Liu YF, et al. Effects of HMGB1 Polymorphisms on the Susceptibility and Progression of Hepatocellular Carcinoma. Int J Med Sci 2016; 13: 304-309.

[32] Wu HH, Liu YF, Yang SF, Lin WL, Chen SC, Han CP, et al. Association of single-nucleotide polymorphisms of high-mobility group box 1 with susceptibility and clinicopathological characteristics of uterine cervical neoplasia in Taiwanese women. Tumour Biol 2016;

[33] Lin CW, Chou YE, Yeh CM, Yang SF, Chuang CY, Liu YF. A functional variant at the miRNA binding site in HMGB1 gene is associated with risk of oral squamous cell carcinoma. Oncotarget 2017; 8: 34630-34642.

[34] Jiang M, Li X, Quan X, Li X, Zhou B. Single Nucleotide Polymorphisms in HMGB1 Correlate with Lung Cancer Risk in the Northeast Chinese Han Population. Molecules 2018; 23:

[35] Bao G, Qu F, He L, Zhao H, Wang N, Ji G, et al. Prognostic Significance of Tag SNP rs1045411 in HMGB1 of the Aggressive Gastric Cancer in a Chinese Population. PLoS One 2016; 11: e0154378. 
[36] Kumari T, Kumar B. High-mobility group box 1 protein (HMGB1) gene polymorphisms and cancer susceptibility: A comprehensive meta-analysis. Clin Chim Acta 2018; 483: 170-182.

[37] Su SC, Hsieh MJ, Lin CW, Chuang CY, Liu YF, Yeh CM, et al. Impact of HOTAIR Gene Polymorphism and Environmental Risk on Oral Cancer. J Dent Res 2018; 97: 717-724.

[38] Murta-Nascimento C, Silverman DT, Kogevinas M, Garcia-Closas M, Rothman N, Tardon A, et al. Risk of bladder cancer associated with family history of cancer: do low-penetrance polymorphisms account for the increase in risk? Cancer Epidemiol Biomarkers Prev 2007; 16: 1595-1600.

[39] Figueroa JD, Ye Y, Siddiq A, Garcia-Closas M, Chatterjee N, Prokunina-Olsson $\mathrm{L}$, et al. Genome-wide association study identifies multiple loci associated with bladder cancer risk. Hum Mol Genet 2014; 23: 1387-1398.

[40] Rothman N, Garcia-Closas M, Chatterjee N, Malats N, Wu X, Figueroa JD, et al. A multi-stage genome-wide association study of bladder cancer identifies multiple susceptibility loci. Nat Genet 2010; 42: 978-984.

[41] Kiemeney LA, Thorlacius S, Sulem P, Geller F, Aben KK, Stacey SN, et al. Sequence variant on $8 \mathrm{q} 24$ confers susceptibility to urinary bladder cancer. Nat Genet 2008; 40: 1307-1312.

[42] Freedman ND, Silverman DT, Hollenbeck AR, Schatzkin A, Abnet CC. Association between smoking and risk of bladder cancer among men and women. Jama 2011; 306: 737-745.

[43] Gandini S, Botteri E, Iodice S, Boniol M, Lowenfels AB, Maisonneuve P, et al. Tobacco smoking and cancer: a meta-analysis. Int J Cancer 2008; 122: 155-164.

[44] Scosyrev E, Noyes K, Feng C, Messing E. Sex and racial differences in bladder cancer presentation and mortality in the US. Cancer 2009; 115: 68-74.

[45] Kang R, Zhang Q, Zeh HJ, 3rd, Lotze MT, Tang D. HMGB1 in cancer: good, bad, or both? Clin Cancer Res 2013; 19: 4046-4057.

[46] Li JH, Liu S, Zhou H, Qu LH, Yang JH. starBase v2.0: decoding miRNA-ceRNA, miRNA-ncRNA and protein-RNA interaction networks from large-scale CLIP-Seq data. Nucleic Acids Res 2014; 42: D92-97.

[47] Mantovani R. A survey of 178 NF-Y binding CCAAT boxes. Nucleic Acids Res 1998; 26: 1135-1143.

[48] van der Krieken SE, Popeijus HE, Mensink RP, Plat J. CCAAT/enhancer binding protein beta in relation to ER stress, inflammation, and metabolic disturbances. Biomed Res Int 2015; 2015: 324815. 